\title{
Strain Behavior in the Restored Edentulous Mandible Bone
}

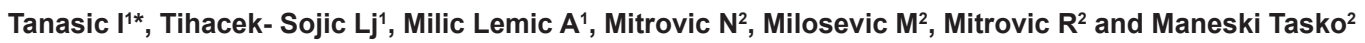

${ }^{1}$ School of Dentistry, University of Belgrade, Belgrade, Serbia

${ }^{2}$ Faculty of Mechanical Engineering, University of Belgrade, Belgrade, Serbia

\begin{abstract}
The aim of this study is to estimate strains in the restored macerate edentulous mandible bone by using the ARAMIS three-dimensional image correlation system. The system uses two digital cameras that provide a synchronized stereo view of the specimen and the results show the complete strain field during the tests. The highest strain $(5 \%)$ was detected within mandible-denture contact, mental foramen $(8 \%)$ and trigonum retromolar $(15 \%)$. The strain is the consequence of the complete denture vertical displacement.
\end{abstract}

Keywords: Edentulous mandible; Complete denture; Strain; Digital image correlation method

\section{Introduction}

Investigations of the biomechanical behaviour of hard tissues are of great importance in investigation, design and improvement of biomaterials for teeth annexes. Success of prosthetic treatment is primarily determined by biomechanical compatibility of the designs with the tissues. The reason is that the tissues are not merely a material, but a composite biological system whose reaction to denture masticatory stress is not sufficiently described in the classical theory of elasticity [1]. The main determinant of bone mechanical properties is mineral content although other features, such as structural anisotropy, histology and, particularly, porosity are also important. The osteon of the bone tissue is made of internal (younger) lamellas which are less mineralized and external (older) lamellas more mineralized. The age changes cause the circulation drop, the increase of mineralized lamellas, the loss of fibroblasts and osteoblasts and the loss of osteoclasts level. The changes of shape and morphology of the residual ridge are parts of the physiological processes of growth, development as well as aging. The main changes in the alveolar bone occur during the loss of teeth [2]. Extractions of all teeth cause the total loss of dental transmission of masticatory forces. The transfer of load for the patientes with acrylic denture is focused to mucous membrane and alveolar bone. The mucous resilience depreciates the masticatory stresses to a certain, but over the time the resorption rate become higher especially in some regions of the mandible. Accordingly it can be arqued about the regions of the restored mandible bone that can suffer from grater deformities (strains) and consequently resorption [2].

The mandible can be evaluated using a number of methods that are based on either contact or noncontact schemes for strain measurement. Many optical methods have recently appeared which verify the virtual patterns and results and are based on direct measuring of bone tissue tested material strains. The mentioned methods register strains very precisely and they have found a broad application in biomedical sciences [3-6]. Unlike many quantitative and qualitative methods to study load-displacement response and stress distribution in bone structure and that are based mainly on measuring strains of whole bones or teeth at single points, or developing constitutive theoretical models that can predict the behavior of the whole bone or tooth based on the biomechanical properties of its individual constituent materials, recent advances in optical methods open up new opportunities as they enable the precise and accurate mapping of the manner in which the entire surface of a whole stiff mineralized tissue deforms [3]. The direct measurements (Speckle Correlation method) of the dentofacial bones strains under the partial acrylic dentures showed the residual strain of 50 micrometres under pressure of 3,0 to $4,4 \mathrm{MPa}$, which is even less than under pressure of 0 to $3,5 \mathrm{MPa}$ [1]. Data deficit about strain of the mandible bone under the lower complete denture base has pointed out the neccessity for the research of these phenomena applying optical method of strain measuring.

The aim of this study is to estimate strains in the restored macerate edentulous mandible by using the optical method of strain measuringdigital image correlation method.

In the null hypothesis it is supposed that the edentulous mandible strains appear under the lower total denture base and that the optical method can register and measure strain in the mandible.

\section{Method and material}

A method is based on direct measuring of strains in the mandible bone. GOM manufacturer's equipment consists of special mobile cameras that phothograph the tested object (mandible bone and complete denture). ARAMIS software (Braunschweig, Germany) processes the photos.

ARAMIS determines the shape of the filmed object, its dimensions, the field of three-dimensional movements, the vector distorted field and the features of the biomaterial. Unlike a tensionmeter or a extensionmeter which give only separate measuring values and which measure deformities by elastic strips at the places where deformities are expected, ARAMIS defines deformity disribution over the whole analyzed area, which enables better understanding of the material behaviour, consructions and the real measuring objects that are used in medicine and dentistry. ARAMIS separates the superficial layer of the tested bone $2 \mathrm{~mm}$ thick and shows strain field over the whole surfice of the phothographed bone.

*Corresponding author: Ivan Tanasic, School of Dentistry, University of Belgrade, Belgrade, Serbia, E-mail: doktorivan@hotmail.com

Received October 24, 2011; Accepted November 08, 2011; Published November 12, 2011

Citation: Tanasic I, Tihacek- Sojic Lj, Milic Lemic A, Mitrovic N, Milosevic M, et al. (2011) Enhanced in-Vivo Bone Formation by Bone Marrow Differentiated Mesenchymal Stem Cells Grown in Chitosan Scaffold. J Bioengineer \& Biomedical Sci 1:107. doi:10.4172/2155-9538.1000107

Copyright: () 2011 Tanasic I, et al. This is an open-access article distributed under the terms of the Creative Commons Attribution License, which permits unrestricted use, distribution, and reproduction in any medium, provided the original author and source are credited. 


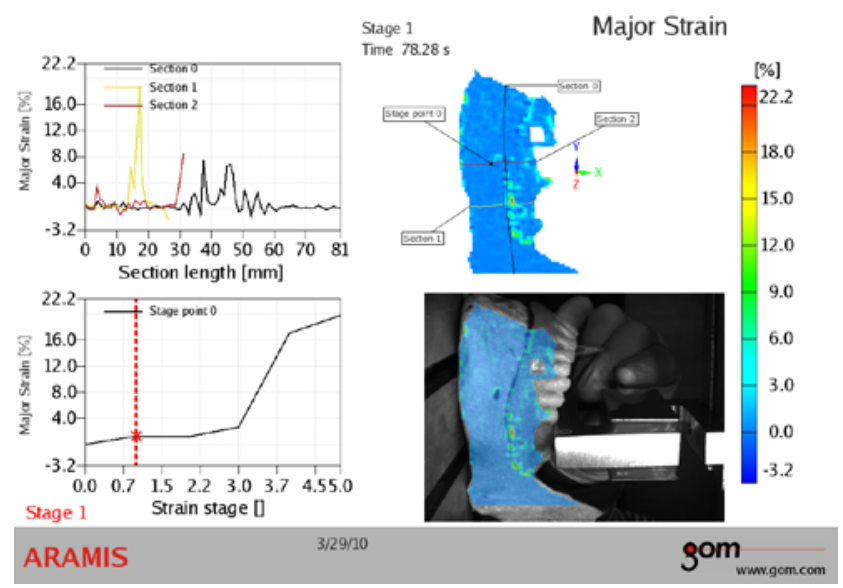

Figure 1: Major strain field within the first of the restored mandible loading

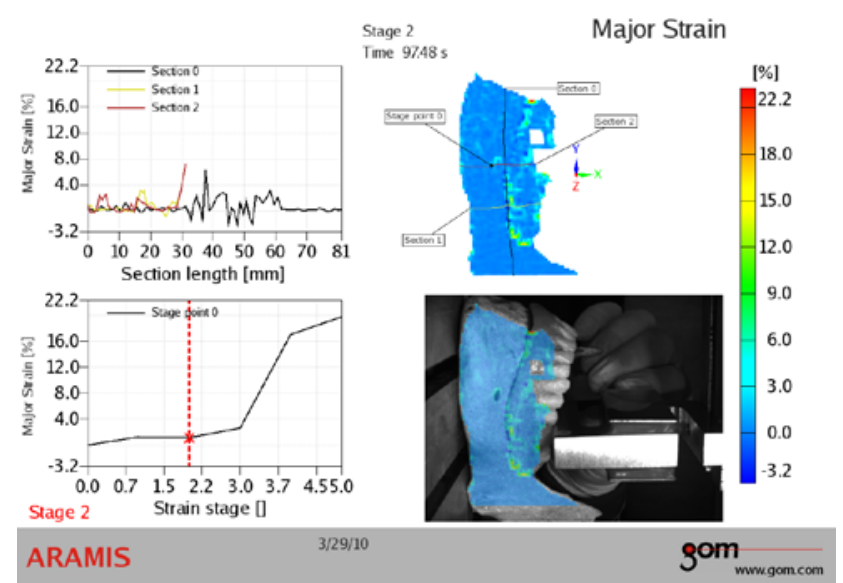

Figure 2: Major strain field within the second of the restored mandible loading

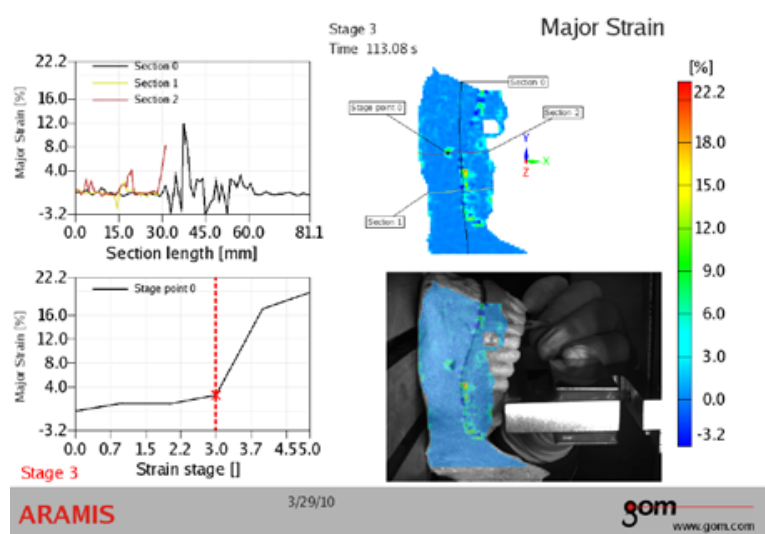

Figure 3: Major strain field within the third of the restored mandible loadin

\section{The preparation of the edentulous lower jaw}

The edentulous mandible (man, 50) and also the lower complete denture made for this mandible were used for this experiment performance. The mandible was previously left in the physiological solution $(0,9 \% \mathrm{Na} \mathrm{Cl})$ in order to reach the volume and elasticity of its internal structure necessary for in vitro investigation [7]. After drying at the temperature of 27 Celsius degrees the mandible is lacquered

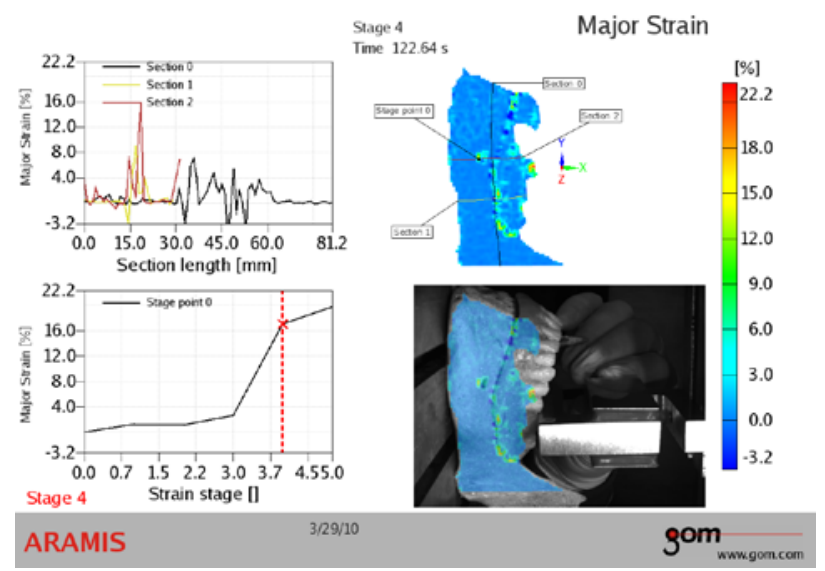

Figure 4: Major strain field within the fourth of the restored mandible loading

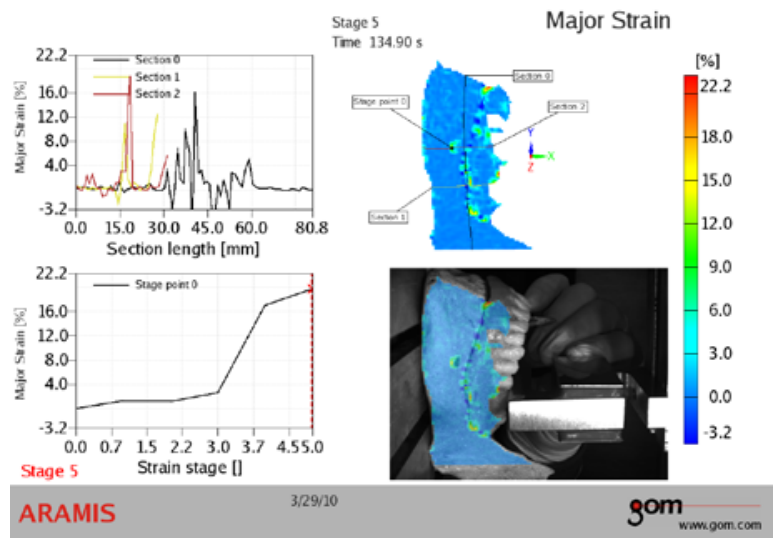

Figure 5: Major strain field within the fifth of the restored mandible loading

with a great density spray. Before exposition to the affect 100 to $500 \mathrm{~N}$ force (load) the lacquered particles (reference points) occupy a certain position and mutual distance. This distance is reduced if mandible bone is loaded. After the impression procedure by elastomer in the custom trey, and manufacturing the lower complete denture, the denture was placed on the residual ridge of the mandible. Consequently, it was made the experimental model (mandible with denture) that was tested in the tensile testing machine [8].

\section{The load direction}

In this research there was the assumption that the mandible was fixed, because the mandible is immobile in the position of central occlusion. In the case that the mandible is mobile, analysis and estimation would be impossible because the load would cause the denture displacement and mandible movement and not strains of the residual alveolar ridge. The dental annexes (replacements) and biological structure of the masticatory system under the influence of mastication forces succumb the same physical laws. Under the influence of the mastication forces there is the distribution of forces from the denture onto mucose and submucose membrane and the residual ridge. The mucose and submucose membrane have a certain level of bending which is different depending in which part of the alveolar ridge it is measured. The value of this mucose and submucose membrane feature hasn 't been taken in account. 
The load influence was directed to the acrylic (Ivoclar) teeth across the horizontal extention of the gnatodynamometer which is used for the purpose of precise and controlled measuring. This horizontal extention is applied to the first and the second left lower molar, contemporaneously. Thanks to digital cameras the changes meaning strains have been photographed.

\section{Results}

\section{Experiment 1}

The major (principle) strain field is shown during buccal and lingual cusps loading of the acrylic teeth (Ivoclar) in the lower total denture. The applied load intensities were from 100 to $500 \mathrm{~N}$ in the intervals of $100 \mathrm{~N}$.

For the vertical / sagittal line (section) shown in the figures, the values of the denture displacements against the mandible are given graphically with diagrams in the left side of each figure (figure project).

This line is set by software under the slams point force which influences on the acrylic first and second lower molar and it changes its length with the change of intensity and the slams point force. The line joins the points of reference obtained in process of lacquering the mandible and denture.

The scale by the figures enable the registering of quantative changes in the mandible-lower complete (total) denture complex, and it is presented in percents. The most intensive changes are located in the mandible bone immediately under the slams point force. Under influence of $500 \mathrm{~N}$ force, percentual value of deformity and lenght reduction of the section line $(\Delta \mathrm{L})$ have the maximal values (Figure 5). Every single load from 100 to $500 \mathrm{~N}$ (with interval of $100 \mathrm{~N}$ ) was followed by one figure-figure project. It means that five figures represent five possible stages. A stage is a moment that registers mandible strain within major strain field (elastic field). Every single stage represents viable and distinct strain values within different loading conditions. The most representative and highest strain value that is located just below the slams point is stage point (the part of the line section). Stage point values are indicated in the Table 1 along with separate strain values for mental foramen and trigonum retromolar. Also, the value of the stage point can be read in the lower diagram, at the point where the red line intersects the black line (line section).

\section{Discussion and conclusion}

In this study by the method of optical strain measuring the adequate analysis of distribution and intensity of the denture-bone complex strain is obtained. The repeatability of the optical measuring is very big with the variation coefficient of $0,5 \%$ [9]. This fact enables us to verify the virtuel models which measure the volume of the bone tissue changes in the forcing function with large precision. The advantage of 3D optical measuring over the method of finite element analysis (FEA) is registering of bone lamellas microdisplacements by direct procedure

\begin{tabular}{|l|l|l|l|l|}
\hline \multicolumn{5}{|c|}{ strain values } \\
\hline Load $[\mathrm{N}]$ & stage & $\begin{array}{l}\text { Stage point } \\
\text { strain }\end{array}$ & $\begin{array}{l}\text { Foramen } \\
\text { mentale }\end{array}$ & $\begin{array}{l}\text { Trigonum retro- } \\
\text { molare }\end{array}$ \\
\hline 100 & 1 & 0.9 & 3 & 6 \\
\hline 200 & 2 & 1.9 & 4 & 9 \\
\hline 300 & 3 & 3.0 & 6 & 12 \\
\hline 400 & 4 & 3.9 & 7 & 14 \\
\hline 500 & 5 & 5.0 & 8 & 15 \\
\hline
\end{tabular}

Table 1: Separate strain values in the mandible bone on the observed segments with the shortened interval of getting the exact results, without scanning. The modelling of soft tissue has not been done in this research, but knowing its thickness and quality, it is considered that it could influence only on the intensity of deformity which would be a bit less, but not on the direction of deformity distribution [10-13]. Generally speaking, in all stages the major strain field has the identical spreading direction with the maximal strain value $(\varepsilon)$ within the denture-bone complex. By interpreting of the major strain fields in the figures it is registered that the strains of the mandible bone in the elastic major strain field are the result of vertical displacements of the lower complete denture acrylic base. During the influence of masticatory and non-masticatory forces on acrylic teeth (molars) of the lower complete denture, the less part of their working intensity is amortized thanks to highly elastic component of polymer materials and non-networked polymers of the arteficial teeth [14]. The initial deflection of the thermal-polymerized acrylats for manufacturing of the lower complete denture base causes the biological reaction of bone tissue in direct contact with the denture. This biological answer is in the form of alveolar extention strain that is in this initial phase (initiation) most expressive and is from 104 to $390 \mu \mathrm{m}$ for the examined region. By increasing the applied forces intensity, the concentric deformed segments are noticed within the major strain field. These segments are especially expressed in the region of foramen mentale and trigonum retromolar and the bone lamellas which are in the direct contact with the acrylic base of the denture. The researches by the method of final elements have shown the similar distribution of strain and deformities [15]. Under working forces which are less than $500 \mathrm{~N}$, displacements of the denture base cause the minimal strains which is shown in the Table 1. By evaluation of the obtained results it is noticed that the strains occur under forcing the denture rehabilitated mandible are more expressive in the molar region of the mandible compared to the premolar region (Table 1). These strains are the biggest in the bone region under the acrylic molars. The large value of strain in fact is a proof that the tested lower complete denture does not have a real, stable support and under the influence of external forces the lower complete denture displaces on the bone tissue [16]. On the data base from the Table 1, it can be noticed that in all five stages the strain value increase is linear and that the highest strain values are just under the working force of the biggest intensity $500 \mathrm{~N}$. It is recorded that with humans the maximal willing force measured in the molar region is $500-700 \mathrm{~N}$, and in the region of incisives 100-200 N. It depends on the total muscular strength. The functional force is similar with those persons who have the fixed tooth annexes and those who have the preserved dentition, while it is reduced with the total denture persons, according to the authors, to the quarter or the fifth of the force measured with persons who have natural teeth [17-19]. It should be pointed out that the forces of $500 \mathrm{~N}$ are the extreme forces for the case of complete edentulism.

\section{Conclusion}

On the base of all mentioned above it can be concluded that

-under loading of the denture rehabilitated edentulous mandible appear strains within the superficial bone layer which are the consequences of the vertical complete denture displacement;

-the most expressive strain is within the upper part of the mandible (residual ridge) especially in the zone of bone-denture contact;

-this project is defined and indicates linear dipendence between two sizes: load and strain;

-higher strain values in the region of mental foramen and trigonum 
Citation: Tanasic I, Tihacek- Sojic Lj, Milic Lemic A, Mitrovic N, Milosevic M, et al. (2011) Enhanced in-Vivo Bone Formation by Bone Marrow Differentiated Mesenchymal Stem Cells Grown in Chitosan Scaffold. J Bioengineer \& Biomedical Sci 1:107. doi:10.4172/2155-9538.1000107

retromolar within the fifth stage compared to previous stages are observed.

\section{References}

1. Kulchin YN, Vitrick OB, Lantsov AD, Vorobyev VA, Moskvin YN (2008) Measuring the Deformity of Dentofacial Bone Tissues Using a Speckle Correlation Method. Optoelectronics, Instrumentation And Data Processing 44: 264-268.

2. Pietrokovski J, Massler M (1967) Alveolar ridge resorption following tooth extraction. Journal of Prosthetic Dentistry 17: 21-27.

3. Shahar R, Weiner S (2007) Insights into whole bone and tooth function using optical metrology. J Mater Sci 42: 8919-8933.

4. Jianying Li J, Foka ASL, Satterthwaite J, Watts DC (2009) Measurement of the full-field polymerization shrinkage and depth of cure of dental composites using digital image correlation. Dental Materials 25: 582-588.

5. Ahn B, Kim J (2010) Measurement and characterization of soft tissue behavior with surface deformation and force response under large deformations. Medical Image Analysis 14: 138-148.

6. Garcia D, Orteu JJ. 3D Deformation Measurement Using Stereocorrelation Applied To Experimental Mechanics; The 10th FIG International Symposium on Deformation Measurements 19 - 22 March 2001 Orange, California, USA p. $50-60$.

7. Arendts FJ, Sigolotto C (1990) Mechanical characteristics of the human mandible, and investigation of the 'in-vivo' reaction of the compact bone: $A$ contribution to the descreption of the biomechanics of the mandible-part II. Biomedizinische Technik 35: 123-130.

8. Tortopidis D, Lyons MF, Baxendale RH, Gilmour WH (1998) The variability of bite force measurement between sessions, in different positions within the dental arch. J Oral Rehabil 25: 681-686
9. Windisch S, Jung R, Sailer I, Studer S, Ender A, et al. (2007) A new optica method to evaluate threedimensional volume changes of alveolar contours: a methodological in vitro study. Clin. Oral Impl. Res 18: 545-551.

10. Kawasaki T, Takayama Y, Yamada T, Notani K (2001) Relationship between the stress distribution and the shape of alveolar residual ridgethree-dimensional behaviour of a lower complete denture. J Oral Rehabil 28: 950-957.

11. Stokes I, Greenapple DM (1985) Measurement of surface deformation of soft tissue. J Biomech 18: 1-7.

12. DuChesne A, Unnewehr M, Schmidt PF, Sotonyi P, Brinkmann B, et al. (2003) Deformation characteristics of the human mandiblein low impact experiments. Int J Legal Med 117: 257-262.

13. Hayakawa I, Akiba N, Keh E, Kasuga Y (2006) Physical properties of a new denture lining material containing a fluoroalkyl methacrylate polymer. J Prosthe Dent 96: 53-58.

14. Panduric J, Husnjak M, Guljas K, Kraljevic K, Zivko-Babic J (1988) The stimulation and calculation of fatigue of the lower complete denture in function by means of the finite element analysis. J Oral Rehabil 25: 560-565.

15. Maeda Y, Wood WW (1989) Finite element method simulation of bone resorption beneath a complete denture. Journal of Dental Research 68: 1370-1373.

16. Muller F, Heath MR, Ott R (2001) Maximum bite force after the replacement of complete dentures. Gerodontology 18: 58-62.

17. Michael CG, Javid NS, Colaizzi FA, Gibbs GH (1990) Biting strength and chewing forces in complete denture wearers. J Prosthet Dent 63: 549-553.

18. Stellingsma K, Slagter AP, Stegenga B, Raghoebar GM, Meijer HJ (2005) Masticatory function in patients with an extremely resorbed mandible restored with mandibular implant-retained overdentures: Comparison of three types of treatment protocols. Journal of Oral Rehabilitation 32: 403-410. 